\title{
A Comparison of the Efficacy and Tolerability of Controlled-Release Carbamazepine with Conventional Carbamazepine
}

\author{
Z. Dhalla, J. Bruni and J. Sutton
}

\begin{abstract}
We compared the efficacy and tolerability of controlled-release carbamazepine (CBZ-CR) with conventional carbamazepine (CBZ) in 131 epileptic patients (both men and women, ages 6-65 years) in an open, multicentre, cross-over trial. Patients entered into the trial were previously on CBZ monotherapy or polytherapy. During the first 4 weeks, patients were treated with equivalent daily doses of $\mathrm{CBZ}$ and then switched to $\mathrm{CBZ}-\mathrm{CR}$ for the subsequent 4 weeks. The majority of patients were switched to the more convenient b.i.d. dosing schedule of the controlled-release (CR) preparation without a detrimental effect on seizure frequency or adverse effects. In 44/131 (34\%) of patients, the switch to $\mathrm{CBZ}$-CR was accompanied by an improvement in tolerability, primarily due to a reduction in peak-dependent CNS side-effects such as tiredness, double or blurred vision, dizziness and ataxia. At the end of the study, investigators preferred CBZ-CR for $76 \%$ of their patients and $70 \%$ of the patients preferred CBZ-CR.
\end{abstract}

RÉSUMÉ: Une comparaison de l'efficacité et de la tolérabilité de la carbamazépine à libération contrôlée à la carbamazépine conventionnelle. Nous avons comparé l'efficacité et la tolérabilité de la carbamazépine à libération contrôlée (CBZ-LC) à celles de la carbamazépine conventionnelle (CBZ) chez 131 épileptiques (hommes et femmes, entre 6 et 65 ans) dans le cadre d'une étude ouverte multicentre, en chassé-croisé. Les patients admis à l'étude étaient antérieurement sous $\mathrm{CBZ}$ en monothérapie ou polythérapie. Pendant les 4 premières semaines, les patients étaient traités par une dose quotidienne équivalente de CBZ, puis transférés au CBZ-LC pour les 4 semaines auivantes. La majorité des patients étaient ensuite mis à une posologie b.i.d. plus commode de la préparation à libération contrôlée, sans effet néfaste sur la fréquence des crises ou des effects secondaires. Chez 44 des 131 patients (34\%), le passage à la CBZ-LC s'accompagnait d'une amélioration dans la tolérabilité, principalement due à la réduction des effets secondaires associés au pic du médicament au niveau du système nerveux central tels que la fatique, la diplopie ou la vision trouble, les vertiges et l'ataxie. À la fin de l'étude, les investigateurs ont préféré la CBZ-LC pour 76\% de leurs patients et $70 \%$ des patients ont préféré la CBZ-LC.

Can. J. Neurol. Sci. 1991; 18: 66-68

Chronic therapy with conventional CBZ may result in a shortened half-life ${ }^{1,2}$ (due to autoinduction) and considerable interdose fluctuations in the serum CBZ and CBZ-10, 11-epoxide concentrations, even when $\mathrm{CBZ}$ is administered in multiple divided daily doses. Fluctuations in the serum CBZ concentration (with reference to mean concentrations) of $40-150 \%$ for $\mathrm{CBZ}$ and $40-500 \%$ for its active metabolite CBZ-10, 11 -epoxide, have been described. ${ }^{3.4}$ These fluctuations, in some patients, may result in intermittent CNS side-effects related to peaks in the serum $\mathrm{CBZ}$ concentration. These side-effects include headache, nausea, fatigue, dizziness, double or blurred vision and ataxia. The frequency of these intermittent CNS side-effects varies considerably (18\%-56\% of patients) depending on how carefully patients are scrutinized..$^{5-9}$

TEGRETOL CR ${ }^{\circledR}$ is a new formulation of $\mathrm{CBZ}$ (CBZ-CR) in which minute $C B Z$ crystals are specially coated to retard gastrointestinal absorption. This reduces the peak serum $\mathrm{CBZ}$ con- centration as well as fluctuations in the serum concentration following oral administration. The potential advantages of such a preparation over conventional CBZ include improved tolerability (by a reduction of peak-dependent CNS side-effects), improved compliance (as a result of b.i.d. dosing) and, in some patients, improved antiepileptic efficacy (by permitting them to tolerate higher total daily dose of CBZ).

We studied the efficacy and tolerability of CBZ-CR with conventional CBZ in epileptic patients previously treated with CBZ monotherapy or polytherapy.

\section{METHODS}

\section{Patient Selection}

131 patients ( 65 men and 66 women) with a variety of seizure types, age 6-65 years, from 13 Canadian centres participated in this open, cross-over study. 96 patients were age 17 and over and

From the Division of Neurology, the Wellesley Hospital and the University of Toronto, Toronto and the Tegretol CR ${ }^{\circledR}$ Study Group Received April 6, 1990. Accepted in final form October 22, 1990 
35 were children and adolescents age 6-17. The majority of patients were well-controlled on CBZ monotherapy or polytherapy prior to entry in the trial.

Patients were excluded if they were receiving any of the following medications; oral anticoagulants, propoxyphene, tetracyclines, clofibrate, MAO inhibitors, tricyclic-antidepressants, erythromycin or theophylline. Patients with known hypersensitivity to $\mathrm{CBZ}$ or tricyclic antidepressants were also excluded. Pregnant patients, those with known organic heart disease, liver, kidney or thyroid disorders, advanced pulmonary disease, tumors with poor prognostic potential, a low platelet count or leukocytosis were also excluded.

\section{Study Design}

All patients were initially treated with conventional $\mathrm{CBZ}$ (TEGRETOL ${ }^{\circledR}$ ) for four weeks at a daily dose equal to that which they were receiving prior to entry. Patients were then switched to CBZ-CR (TEGRETOL CR ${ }^{\circledR}$ ) b.i.d. at the same total daily dose for the subsequent four weeks. The daily dose of CBZ and concomitant antiepileptic drugs was not changed during the trial unless unacceptable changes in seizure frequency or adverse effects occurred, and any changes were recorded.

\section{Clinical Monitoring}

At the first visit, each patient had a complete history and physical examination. All eligible patients, or their legal parent or guardian, gave written informed consent. Patients were monitored every two weeks during the eight week trial period. At each visit, patients were supplied with two weeks of trial medication and the type and frequency of seizures, adverse effects and morning fasting (footpoint) plasma CBZ levels were recorded. Laboratory tests of hematologic and liver function were performed at the initial visit and thereafter at the fourth and eighth week. Compliance was assessed by counts of unused tablets at the end of each 2 week period or at premature discontinuation. At the end of the study, both investigators and patients were asked to rate the efficacy, tolerability and preference of each of the two CBZ formulations.

\section{CBZ Dosing}

At the initial visit, the percentage of patients receiving a given number of daily CBZ doses was as follows: 3 doses $38 \%, 2$ doses $-33 \%, 4$ doses $-21 \%, 5$ doses $-4 \%$ and 1 dose $4 \%$. After the fourth week, all patients were switched to an equivalent daily dose of CBZ-CR b.i.d.

\section{Premature Terminations}

10 patients $(7 \%)$ terminated prematurely. Five terminated because of uncontrolled seizures ( 3 during the CBZ phase, and 2 during the CBZ-CR phase). One patient was lost to follow-up in the $C B Z$ phase, one experienced adverse effects on the CBZ phase, one was excluded because of a medication error and no reason was given for the remaining two premature terminations, one of which occurred during the CBZ phase, and one in the CR phase.

\section{Results}

\section{Efficacy and Tolerability}

Table 1 shows the investigators' ratings of antiepileptic efficacy and tolerability. The majority of patients (115/131 or $89 \%$ ) experienced either the same or better antiepileptic efficacy on the CR preparation compared to conventional CBZ. With regard to tolerability, the results were similar with $119 / 131$ patients or 91\% experiencing equivalent or improved adverse reactions (mainly in peak-dependent CNS side-effects). Overall, 44/131 or $34 \%$ of patients tolerated the CR preparation better. Of the peak-dependent side-effects that were assessed as improved, fatigue $(18 \%)$, double or blurred vision (13\%), dizziness $(12 \%)$ and ataxia (11\%) were the most improved.

No clinically significant changes in hematologic or hepatic function tests were observed. Table 2 shows that there is no statistically significant difference in the mean footpoint plasma CBZ level for the two CBZ preparations.

\section{Compliance}

Compliance (percent of patients between $80 \%$ and $120 \%$ compliant), as assessed by counts of unused tablets, was similar for the two groups ( $86 \%$ for CBZ and $79 \%$ for CBZ-CR). 9/131 (7\%) of patients on the $\mathrm{CR}$ preparation were $>120 \%$ compliant compared to $1(1 \%)$ on conventional $\mathrm{CBZ}$, suggesting that some patients in the $C R$ phase may have inadvertently taken the $C R$ preparation more often than b.i.d.

\section{Overall Preference}

At the end of the study, both investigators and patients were asked which of the two preparations they preferred. The investigators preferred the CR preparation for $76 \%$ of their patients and $70 \%$ of the patients preferred the CR preparation. The conven-

Table 1: Investigators Rating of Overall Efficacy and Tolerability of CBZ-CR Compared to Conventional CBZ.

\begin{tabular}{lrr}
\hline \hline & $\begin{array}{c}\text { Efficacy } \\
\text { (No. of Patients) }\end{array}$ & $\begin{array}{c}\text { Tolerability } \\
\text { (No. of Patients) }\end{array}$ \\
\hline Much better & $15(12 \%)$ & $21(16 \%)$ \\
Better & $18(14 \%)$ & $23(18 \%)$ \\
Same & $82(63 \%)$ & $75(57 \%)$ \\
Worse & $8(6 \%)$ & $5(4 \%)$ \\
Much worse & $2(1 \%)$ & $1(1 \%)$ \\
No data & $6(4 \%)$ & $6(4 \%)$ \\
Total & $131(100 \%)$ & $131(100 \%)$ \\
\hline
\end{tabular}

Table 2: Mean Footpoint Plasma CBZ Levels

\begin{tabular}{clc}
\hline \hline $\begin{array}{c}\text { Weeks of } \\
\text { Treatment }\end{array}$ & \multicolumn{2}{c}{ Mean Footpoint CBZ Level } \\
Conv. CBZ & CBZ-CR \\
\hline 2 & $27.56 \pm 10.08$ & $27.56 \pm 9.43$ \\
4 & $28.14 \pm 9.45$ & $27.95 \pm 9.84$ \\
\hline
\end{tabular}


tional preparation was preferred by investigators for $5 \%$ of their patients and $11 \%$ of patients preferred conventional CBZ. The main reasons given by both groups for the preference of the $C R$ preparation included the convenience of b.i.d. dosing and improved tolerability.

\section{Discussion}

The main finding of this study is that the majority of patients on multiple daily doses of conventional $\mathrm{CBZ}$ could be switched to an equivalent daily dose of CBZ-CR b.i.d. without a detrimental effect on seizure frequency or adverse effects. In $34 \%$ of patients, the switch to the CR preparation was accompanied by an improvement in tolerability, primarily in the peak-dependent CNS side-effects such as fatigue, double or blurred vision, dizziness and ataxia. This finding is consistent with the pharmacokinetic profile of CBZ-CR which is characterized by smaller fluctuations in the serum $\mathrm{CBZ}$ concentration compared to conventional CBZ.

The majority of patients on CBZ-CR experienced equivalent or improved antiepileptic efficacy ( $89 \%$ of patients) and tolerability (91\% of patients) compared to conventional CBZ. However, because of the relatively short duration of the study, and because the study was not randomized or blinded, no firm statement can be made regarding antiepileptic efficacy. Neither the patients nor the investigators could easily be blinded due to differences in the appearance of the CBZ preparations. The two groups showed similar mean footpoint (or trough) plasma CBZ levels.

Compliance was similar for the two groups. At the end of the study both investigators and patients showed a preference for the CR preparation with the convenience of b.i.d. dosing and improved tolerability being cited as the main reasons for the preference.

\section{Previous Experience with Controlled-release CBZ Preparations}

Most of the literature comparing controlled-release $\mathrm{CBZ}$ preparations with conventional $\mathrm{CBZ}$ has emanated from numerous European studies. Most of these have been small (involving less than 30 patients) with open, cross-over designs. A few studies have involved larger numbers of patients (40-473 patients). Most of these studies ${ }^{10-18}$ have found equivalent antiepileptic efficacy, improved tolerability and compliance on the controlledrelease $C B Z$ preparation. In some studies 10,12 patients taking the controlled-release $\mathrm{CBZ}$ preparation were able to tolerate higher total daily doses of $\mathrm{CBZ}$ resulting in improved antiepileptic efficacy. Most patients in these studies showed a preference for the controlled-release $\mathrm{CBZ}$ preparation.

\section{ACKNOWLEDGEMENTS}

The TEGRETOL $\mathrm{CR}^{\circledR}{ }^{\circledR}$ study group included F. Andermann (Montreal), M. Beaulieu (Montreal), W. Blume (London), J. Bruni (Toronto), P. Camfield (Halifax), E. Gauk (Edmonton), M. Gawel (Toronto), M. Jones (Vancouver), G. Klein (Calgary), P. Langevin (SteFoy, Quebec), M. Lee (Calgary) and E. Starreveld (Edmonton). We wish to thank CIBA-GEIGY CANADA LIMITED for supplying TEGRETOL ${ }^{\circledR}$ and TEGRETOL CR $^{\circledR}$ for the study. We thank Ms Farida Hasin and Ms Anna Hwang for typing the manuscript.

\section{REFERENCES}

1. Eichelbaum M, Ekbom J, Bertilsson L, et al. Plasma kinetics of carbamazepine and its epoxide metabolite in man after single and multiple doses. Eur J Clin Pharmacol 1975; 8: 337-41.

2. Eichelbaum M, Bertilsson L, Rane A, et al. Autoinduction of carbamazepine metabolism in man. In: Anticonvulsant Drugs and Enzyme Induction. Richens A, Woodford B, eds. Amsterdam: Associated Scientific Publishers 1976; 147-158.

3. Macphee GJA, Butler E, Bordi MJ. Intradose and circadian variation in circulating carbamazepine and its epoxide in epileptic patients: A consequence of autoinduction of metabolism. Epilepsia 1987; 28(3): 286-294.

4. Paxton JW, Aman MG, Wery JS. Fluctuations in salivary carbamazepine and carbamazepine-10, 11-epoxide concentration during the day in epileptic children. Epilepsia 1983; 24: 716-724.

5. Hoppener RJ, Juyer A, Meijer JWA, et al. Correlations between daily fluctuations of carbamazepine serum levels and intermittent side-effects. Epilepsia 1980; $21: 341-50$.

6. Tomson $T$. Interdosage fluctuations in plasma carbamazepine concentrations determine intermittent side-effects. Arch Neurol 1984; 41: 830-4.

7. Gillham RA, Williams N, Weidman K, et al. Concentration-effect relationship with carbamazepine and its epoxide on psychomotor and cognitive function. J Neurol, Neurosurg, Psychiatry 1988; 51: 929-933.

8. Riva R, Albani F, Ambroselto G, et al. Diurnal fluctuations in free and total steady-state plasma levels of carbamazepine and correlations with intermittent side-effects. Epilepsia 1984; 25: 476481.

9. Riva R, Contin M, Albani F, et al. Free and total plasma concentrations of carbamazepine and carbamazepine-10, 11-epoxide in epileptic patients: Diurnal fluctuations and relationship with side-effects. Ther Drug Monit 1984; 6: 408-13.

10. Canger $\mathrm{R}$, et al. Conventional versus controlled-release carbamazepine: A multicentre, double-blind cross-over study. Bol Lega Ital Epilepsia (l) 1988; 62/63: 419-421

11. Stoll KD, Kraemer G, Berger A. Tegretol 400 retard in epilepsy: results of a multicentre study with 473 patients. In Carbamazepin in der Neurologie. Symp Mainz, Jan 1987. Hrsg V, Kraemer VG, und Hopf-Stuttgart HC, eds. New York: Thieme, 1987: 259-266.

12. Stenzel E. Carbamazepine slow-release in the treatment of epilepsy report on clinical experience. Akt Neurol (D) 1987; 14(4): 127 131.

13. Kraemer G, Stol KD. Tegretol 400 retard in Trigeminal Neuralgia: results of a multicentre study with 93 patients. $I n$ : Carbamazepin in der Neurologie. Symp., Mainz, Jan 1987. Hsrg V, Kraemer VG, und Hopf-Stuttgart HC, eds. New York: Thieme, 1987: 267271.

14. Stefan $\mathrm{H}$, Schaefer $\mathrm{H}$, Kuhnen $\mathrm{C}$. Clinical monitoring during carbamazepine slow-release, once-daily monotherapy. Epilepsia 1988; 29: $571-577$.

15. Blankenhorn V, Buelau $P$, Kraemer $G$, et al. Tegretol 400 retard versus Tegretol 200 in the treatment of severe partial-epilepsy. A 1 -year study. $I n$ : Carbamazepin in der Neurologie. Symp. Mainz, Jan. 1987. Hsrg V, Kraemer VG, und Hopf-Stuttgart HC, eds. New York: Thieme, 1987: 254-258.

16. Haas $S$, Besser R, Hoffman F, et al. Clinical results on changing from Tegretol 200 to Tegretol 400 retard. In: Carbamazepin in der Neurologie. Symp., Mainz, Jan. 1987. Hsrg V, Kraemer VG, und Hopf-Stuttgart HC, eds. New York: Thieme, 1987: 246-248.

17. Besser R, Kraemer G, Katzmann K, et al. Tegretol 400 retard steady-state kinetics in hospitalized and ambulatory patients. I $n$ : Carbamazepin in der Neurologie. Symp., Mainz, Jan. 1987. Hsrg V, Kraemer VG, und Hopf-Stuttgart HC, eds. New York: Thieme, 1987: 225-230.

18. Von Albert HH, Reith H, Schaefer H. Carbamazepine therapy in epileptic patients: First results with a sustained release tablet. (Abstr.) J Neurol 1985, 232 Suppl, 259. 